Research article

JMCJMS

\title{
Evaluation of Genotype MTBDRplus Assay for identifying Multidrug Resistant Mycobacterium tuberculosis isolates in Nepal
}

\author{
Dahal B1,4* , Adhikari N ${ }^{2,3}$, Shah $\mathrm{Y}^{1,3}$, Simkhada RC1,4, Maharjan B ${ }^{4}$, Shrestha B \\ German Nepal Tuberculosis Project (GENETUP) Hospital, National Reference Laboratory, \\ Kathmandu.
}

${ }^{1}$ Kathmandu College of Science \& Technology, Kalimati, Kathmandu, Nepal,

${ }^{2}$ Department of Microbiology, Janaki Medical College, Janakpur, Nepal,

${ }^{3}$ Everest International Clinic \& Research Center, Kathmandu, Nepal,

\begin{abstract}
Background and Objectives: Multidrug-resistant (MDR) Mycobacterium tuberculosis strains are serious threats to the control of tuberculosis and comprise an increasing public health problem. Rapid detection of such strains is quite critical in timely management of such issues. The study was performed with an objective to compare Genotype MTBDRplus reverse hybridization probe assay (Hain Lifescince, GmBH, Nehern, Germany) with culture based proportion method for rapidly identifying MDR-TB strains from suspected multi drug resistant cases, referred to GENETUP Kathmandu, Nepal.

Methodology: A commercially available new Genotype MTBDRplus assay was evaluated for its ability to detect mutations in Mycobacterial isolates conferring resistance to rifampicin (RMP) and isoniazid (INH). A total of 64 MDR isolates (i.e., at least resistant to RMP and INH), 5 fully susceptible strains and 1 RMP sensitive strains by conventional proportion method were analyzed using Genotype MTBDRplus assay. MTBDRplus assay is designed to detect the mutations in the hot spot region of rpoB gene, katG and regulatory region of inhA gene.

Results: The MTBDRplus assay detected 59 of 61 RMP resistant strains (96.72\%) with mutations on 81-bp hot spot region of rpoB gene and 60 of 63 INH resistant strains (95.23\%) with mutation in codon $315 \mathrm{katG}$ and regulatory region of inhA. The sensitivity and specificity for the detection of RMP resistance were $96.72 \%$ and $100 \%$ respectively. While, value of the same two variables for INH resistance were $95.23 \%$ and $100 \%$, respectively.

Conclusions: The new Genotype MTBDRplus assay represents a rapid, reliable, upgraded tool with high sensitivity and specificity for the detection of INH and RMP resistance strains that can readily be included in a routine laboratory work for the early diagnosis and control of MDR-TB.

Keywords: Conventional DST, Genotype MTBDRplus assay, inhA, katG, MDR-TB, rpoB.
\end{abstract}




\section{INTRODUCTION}

Tuberculosis presents a significant health threat to the world's population, with 8 million new cases of disease and 2 million deaths per year [1]. Drug-resistant TB is increasing in many parts of the world, and high rates of multidrugresistant TB-causing (MDR-TB) isolate, resistant to at least isoniazid [INH] and rifampin [RMP], have been reported in several countries [2]. 450,000 new MDR-TB cases are estimated to occur every year [1]. One of the most alarming trends concerning tuberculosis is the emergence of drug-resistant Mycobacterium tuberculosis strains, which has become a global public health problem [3].

In Nepal latest survey conducted in $2001 / 2002$ showed MDR-TB constitutes of $1.3 \%$ of initial TB cases, $20.4 \%$ in acquired cases and $2.4 \%$ of TB patients were co-infected with HIV [4]. The worldwide increase in the rates of multidrugresistant (MDR) tuberculosis has made the timely identification of resistant Mycobacterium tuberculosis strains extremely important to achieve effective diseases management to prevent their spread. INH and RMP are the most important first-line antituberculosis drugs and resistance to these drugs often results in treatment failures and fatal clinical outcomes [5].

MDR strains are serious threats to the control of tuberculosis and comprise an increasing public health problem. Patients infected with MDR strains, are difficult to cure and more likely to remain sources of infection for a longer period of time than are patients with drug-susceptible strains [6]. Treatment for MDR TB patients required use of second - line drugs for more than 24 months. These drugs are more costly, toxic, and less effective than first-line drug used for routine treatment of TB [7].

In a research performed by Ghimire et al., high rates of MDR-TB isolates were obtained in Nepal. Among the total studied cases, $12.9 \%$ isolates were resistant to one or more antituberculosis drug (Rifampicin, Ethambutol, and Isoniazid \& Streptomycin) with initial and acquired MDR $4.6 \%$ and $5 \%$ of the isolated respectively [8]. This indicated the utmost requirement of a tool for rapid detection of such MDR strains for timely management of such issues. The present study aimed to determine the sensitivity and specificity of MTBDRplus assay for the rapid detection of INH and RMP resistance-associated mutations in rpoB, katG and inhA genes from culture specimens in comparison with conventional drug susceptibility testing as a Gold standard.

\section{MATERIALS AND METHODS}

A total of 77 sputum specimens collected from suspected and confirmed MDR-TB patients, resistant to at least isoniazid and rifampicin, visiting different DOTS plus centers of Nepal and referred to German Nepal Tuberculosis Project (GENETUP) Hospital, National Reference Laboratory, Kathmandu.

\section{Sample Collection and processing}

The sputum specimens of MDR-TB suspected patients were sent from different DOTS plus centers in five development regions of Nepal in leak proof, wide mouth, transparent, sterile and stoppered plastic containers were obtained. All collected sputum specimens were processed for Fluorescence microscopy, culture on Lowenstein-Jensen medium by proportion method which were then analyzed by Genotype MTBDRplus assay. 


\section{Conventional Drug Susceptibility Test}

Several 100-fold serial bacilli dilutions were inoculated into drug-containing and drug-free (control) media. The number of colonies obtained in the drug-containing and control media were enumerated. If the proportion of resistant bacteria was higher than $1 \%$ for isoniazid, rifampicin and para-aminosalycilic acid, or $10 \%$ for the other drugs, the strain was considered resistant and the results were taken otherwise, the test was read again at 42 days of incubation to assess if the strain was susceptible to a certain drug [9].

\section{Genotype MTBDRplus assay}

This assay was performed as per standard protocol provided by the manufacturer (Hain Lifescience $\mathrm{GmbH}$, Nehren, Germany). Briefly it was performed in three steps.

1. DNA extraction: A few colonies of pure culture were suspended in $300 \mu$ l of DNA free water in an extraction tube. The suspension was heated at $95^{\circ} \mathrm{C}$ for 20 minutes and then incubated for 15 minutes in an ultrasonic bath. The content was centrifuged at 13,000Xg for 8 minutes. A clear supernatant containing DNA genome was transfer to new tube and used for PCR.

\section{Amplification process in multiplex PCR:}

For amplification, the mixture contained $35 \mu$ l of the primer nucleotide mix, $5 \mu \mathrm{l}$ of $10 \mathrm{X}$ polymerase incubation buffer, $2 \mu$ l of $25 \mathrm{mM}$ $\mathrm{MgCl}_{2}, 0.2 \mu \mathrm{l}$ of AmpliTaq Gold polymerase (5U/I; Applied Biosystems),3 3 l of DNA free water and $5 \mu \mathrm{l}$ of the supernatant of the cell lysate, for a final volume of $50 \mu \mathrm{l}$ was prepared. The amplification protocol consisted of 5 minutes of denaturation at $95^{\circ} \mathrm{C}$ and 2 minutes at $58^{\circ} \mathrm{C}$, an additional 20 cycles comprising 25 seconds at $95^{\circ} \mathrm{C}, 40$ seconds at $53^{\circ} \mathrm{C}$ and 40 seconds at $70^{\circ} \mathrm{C}$ and then a final extension at $70^{\circ} \mathrm{C}$ for 8 minutes.

Hybridization (performed as per the protocol by Hain Lifescience GmbH, Nehren, Germany)

Briefly, $20 \mu \mathrm{l}$ of denaturation solution (DEN, blue) was dispensed in a corner of each of the wells used. Amplified solution of $20 \mu \mathrm{l}$ was added and pipetted up and down to mix well then incubated at room temperature for 5 minutes. $1 \mathrm{ml}$ of prewarmed hybridization buffer (HYB, green) was carefully added, then gently shaked the tray until the solution had a homogenous colour. DNA strip was placed in each well. The tray was placed in shaking water bath/Twincubator and incubated for 30 minutes at $45^{\circ} \mathrm{C}$. Hybridization buffer was completely aspirated out. $1 \mathrm{ml}$ of stringent wash solution (STR, red) was added to each strip and incubated for 15 minutes at $45^{\circ} \mathrm{C}$ in shaking water bath/twincubator. The following steps were performed at room temperature. Stringent wash solution was completely removed. Each strip was washed once with $1 \mathrm{ml}$ of rinse solution (RIN) for 1 minute on shaking platform/twincubator and RIN was poured out after incubation. $1 \mathrm{ml}$ of diluted conjugate was added to each strips and incubated for 30 minutes on twincubator. The solution was removed and washed each strip for 1 minute with $1 \mathrm{ml}$ of Rinse solution and once for 1 minute with $1 \mathrm{ml}$ distilled water and poured out solution each time. $1 \mathrm{ml}$ of diluted substrate (1:100) dimethyl sulfoxide was added to each strip and incubated protected from light without shaking for approximately 10 minutes. Reaction was stopped by briefly rinsing twice with distilled water. 
Strips were removed by using tweezers from tray and dried them between two layers of absorbent paper.

\section{RESULTS}

\section{Total MDR cases:}

Out of total 77 sputum specimens, 70 samples were detected as MDR cases by conventional drug susceptibility testing by proportion method, remaining 7 samples were detected as Atypical mycobacterium.

Figure 1: MDR cases $(n=70)$ from different development region

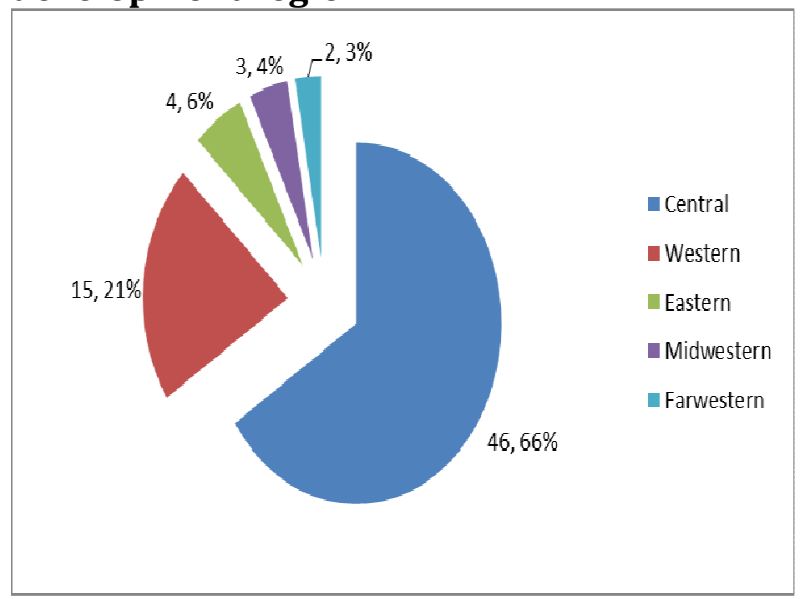

Table 1: Gender of MDR cases studied

\begin{tabular}{l|l|l}
\hline $\begin{array}{l}\text { Sex of MDR } \\
\text { patients }\end{array}$ & $\begin{array}{l}\text { No. of } \\
\text { Patients }\end{array}$ & $\begin{array}{l}\text { Percentage } \\
(\%)\end{array}$ \\
\hline Male & 59 & 84.69 \\
Female & 11 & 15.71 \\
\hline Total & 70 & 100.00 \\
\hline
\end{tabular}

Out of 70 MDR cases obtained 66\% (46) were from central, $21 \%$ (15) were from western, $6 \%$ (4) were from eastern, 4\% (3) were from Midwestern and 3\% (2) were from far-western region.
Out of total 70 MDR- TB patients 59(84.69\%) were male and $11(15.71 \%)$ were female.

All 70 MDR were analyzed for conventional drug sensitivity test by proportion method. Out of which $52.85 \%$ (37) were found to be resistant to all first line drugs, $35.71 \%$ (25) were resistant to RMP and INH, 5.71\%(4) were sensitive to RMP only and $5.71 \%$ (4) were sensitive to all drugs (Table 2).

Table 2: Result of Conventional Drug Susceptibility Test:

\begin{tabular}{l|l|l}
\hline $\begin{array}{l}\text { Result of Drug } \\
\text { sensitivity test }\end{array}$ & $\begin{array}{l}\text { No. of } \\
\text { Isolates }\end{array}$ & $\begin{array}{l}\text { Percentage } \\
(\%)\end{array}$ \\
\hline $\begin{array}{l}\text { All drugs sensitive } \\
\text { All drugs resistant }\end{array}$ & 4 & 5.71 \\
$\begin{array}{l}\text { INH and RMP } \\
\text { resistant }\end{array}$ & 25 & 52.85 \\
RMP sensitive & 4 & 35.71 \\
\hline
\end{tabular}

Though MTBDR assay was performed for 70 isolates, in which 13 different hybridization patterns were observed with 11 specific mutations on $81 \mathrm{bp}$ hot spot region of rpoB gene with 26 isolates showing the specific nucleotide exchange TCG to TTG, resulting in the amino acid exchange of serine to leucine. Other mutations were detected in rpoB codon 526 in 2 strains and rpoB codon 516 in 4 strains (Table 3 ).

Mutation in katG codon315 was detected in 50 of the 70 MDR isolates of which 50 isolates carried the ACC (S315T1 Ser-Thr) mutation (Table 3). 16 isolates had not shown any mutation pattern on the katG 315 codon. 10 (14.29\%) of the MDR isolates that showed a wild-type hybridization pattern in the katG 315 genetic code revealed mutation pattern in the ribosome binding site region of inhA. 
Table 3: Summary of mutations associated with RMP and INH resistance by Genotype MTBDRplus assay

\begin{tabular}{|c|c|c|}
\hline \multicolumn{3}{|c|}{ RMP resistance patter ns (rpoB gene) (n=70) } \\
\hline No(\%) of Isolates & $\begin{array}{l}\text { MTBDRplus assay RMP mutation pattern } \\
\text { (rpoB gene) }\end{array}$ & Result \\
\hline $26(37.14 \%)$ & $\Delta \mathrm{WT} 8, \mathrm{MUT3}$ & RMPr \\
\hline $4(5.71 \%)$ & $\Delta \mathrm{WT} 3,4, \mathrm{MUT} 1$ & $\mathrm{RMPr}$ \\
\hline $1(1.42 \%)$ & $\Delta \mathrm{WT7}, \mathrm{MUT} 2 \mathrm{~A}$ & $\mathrm{RMPr}$ \\
\hline $1(1.42 \%)$ & $\Delta \mathrm{WT7}, \mathrm{MUT} 2 \mathrm{~B}$ & $\mathrm{RMPr}$ \\
\hline $27(38.57 \%)$ & $\Delta(\mathrm{WT7}, \mathrm{WT} 8, \mathrm{WT} 2,3, \mathrm{WT} 4)$ & RMPr \\
\hline $11(15.71 \%)$ & WT & RMPs \\
\hline \multicolumn{3}{|c|}{ INH resistance pattern (katG and inhA gene) $(n=70)$} \\
\hline No(\%) of Isolates & MTBDRplus assay INH pattern (inhA gene) & Result \\
\hline $9(12.85 \%)$ & $\Delta \mathrm{WT} 1, \mathrm{MUT1}$ & $\mathrm{INH}^{\mathrm{r}}$ \\
\hline $1(1.42 \%)$ & $\Delta \mathrm{WT} 2$ & INHr \\
\hline $60(85.71 \%)$ & WT & $\mathrm{INH}^{\mathrm{s}}$ \\
\hline No(\%) of Isolates & MTBDRplus assay INH pattern(katG gene) & Result \\
\hline $50(71.42 \%)$ & $\Delta \mathrm{WT}, \mathrm{MUT1}$ & $\mathrm{INH}^{\mathrm{r}}$ \\
\hline $4(5.71 \%)$ & $\Delta \mathrm{WT}$ & INHr \\
\hline $16(22.85 \%)$ & WT & $\mathrm{INH}^{\mathrm{s}}$ \\
\hline
\end{tabular}

Table 4: Comparison of INH resistance by Conventional DST and Genotype MTBDRplus assay

\begin{tabular}{l|l|l|l}
\hline MTBDRplus assay & \multicolumn{2}{|c}{ Conventional } & DST \\
\hline & $\mathrm{INH}^{\mathrm{r}}$ & $\mathrm{INH}^{\mathrm{s}}$ & \\
$\mathrm{INH}^{\mathrm{r}}$ & 60 & 0 & 60 \\
$\mathrm{INH}^{\mathrm{s}}$ & 3 & 7 & 10 \\
\hline Total & 63 & 7 & 70 \\
\hline
\end{tabular}

Table 5: Comparison of RMP Resistance by Conventional DST and Genotype MTBDRplus assay

\begin{tabular}{|c|c|c|c|}
\hline MTBDRplus assay & \multicolumn{2}{|c|}{ Conventional DST } & Total \\
\hline & $\mathrm{RMPr}$ & RMPs & \\
\hline $\mathrm{RMPr}$ & 59 & 0 & 59 \\
\hline RMPs & 2 & 9 & 11 \\
\hline Total & 61 & 9 & 70 \\
\hline
\end{tabular}


Among 63 INH resistant isolates identified by conventional drug susceptibility testing by proportion method, MTBDRplus assay detected 60 strains as INH resistant and 3 strains as INH susceptible while all of 7 susceptible strains known by conventional DST were diagnosed as sensitive by the assay (Table 4). While comparing the MTBDRplus assay with Conventional Drug Sensitivity as gold standard for the detection of INH resistance, the sensitivity was $95.23 \%$, specificity was $100 \%$, predictive value of positive test was $100 \%$, predictive value of negative test was $70 \%$, percentage of false negative was $4.76 \%$ and percentage of false positive was $0 \%$.

Out of 61 RMP resistant isolates identified by conventional DST, Genotype MTBDRplus assay detected 59 strains as RMP resistant and 2 strains as RMP sensitive. Among 9 RMP susceptible strains diagnosed as RMP sensitive by conventional DST all were detected as RMP susceptible by the assay (Table 5). While comparing the MTBDRplus assay with Conventional Drug Sensitivity as gold standard for the detection of RMP resistance, the sensitivity was $96.72 \%$, specificity was $100 \%$, predictive value of positive test was $100 \%$, predictive value of negative test was $81.81 \%$, percentage of false negative was $3.27 \%$ and percentage of false positive was $0 \%$.

\section{DISCUSSION}

Drug resistance in Mycobacterium tuberculosis isolates is the result of random genetic mutations in particular genes conferring resistance. Drug resistance in those clinical isolates can be assessed rapidly within one working day by molecular assay. The Genotype MTBDRplus assay allows rapid and specific detection of the most-frequent mutations leading to INH and RMP resistance [10].
A useful strategy for diagnosis of drug resistance to RMP in Mycobacterium tuberculosis is the detection of mutations in rpoB gene because mutations in the $81 \mathrm{bp}$ hot spot region of rpoB are predominant (average, 95\%) [11]. Additional analysis of codon 315 of katG facilitates the detection of the most-frequent mutations associated with INH resistance [12]. The test has an advantage of multiplex PCR in combination with reverse hybridization followed by biotin-streptavidin- mediated detection of hybridized PCR fragments on membrane strips coated with target-specific oligonucleotides. The presence of wild-type or mutated DNA sequences in the 81-bp hot spot region of rpoB ,codon 315 of katG and regulatory region of inhA gene is then shown by clear-cut hybridization signals on the membrane strips and the results are easy to interpret without the extensive expert knowledge. The new MTBDRplus assay can even be applied directly to smear-positive specimens, with a turnaround time of approximately $6 \mathrm{hr}$., and save several weeks of time required for conventional DST.

The Genotype MTBDRplus assay detected 96.72\% of possible mutations conferring RMP resistance. $3.27 \%$ of the isolates phenotypically resistant to RMP were classified as susceptible by Genotype MTBDRplus assay due to the presence of a hybridization pattern typical for the wild type sequences in the rpoB hot spot region. These strains carried mutation in codon outside the $81 \mathrm{bp}$ hot spot region of rpoB gene, which was not included in the DNA strip (may be point mutations). Besides, none of the 9 susceptible isolates carried a mutation in this region. From the results, the Genotype MTBDRplus assay revealed a high sensitivity and specificity $96.72 \%$ and $100 \%$, respectively for RMP resistance compared to the 
conventional DST. The PV+ and PV- was $100 \%$ and $81.81 \%$ respectively.

Concerning INH resistance, mutation in either inhA or katG gene or both confer resistance to INH. INH resistance of isolates by MTBDRplus assay was found to have overall sensitivity and specificity of $95.23 \%$ and $100 \%$. The PV+ and PV- was $100 \%$ and $70 \%$ respectively. The lower value of sensitivity and PV- is due to the three phenotypically resistant strains (4.76\%). The hybridization pattern in these strains were typical for wild type sequences in both katG and inhA regulatory region. The mutations conferring the resistance in these could be outside the targeted inhA or katG regions. Hence they were detected as susceptible by MTBDRplus assay.

This result obtained is in accordance with the results obtained from previous research carried out by several researchers. These researches affirm usefulness of MTBDRplus assay for detection of INH and RMP resistance directly from sputum samples. All of these researches report high sensitivity, specificity of the MTBDRplus assay [10], [13], [14], [15]. Bazira et. al.2010, used and concluded that Genotype MTBDRplus assay can be used for rapid screening of MDR-TB in rural settings [16]. They employed both newly diagnosed as well as previously treated cases to assess drug resistance. High prevalence of mutations within the rpoB core region (96.72\%), as well as of mutations at katG codon 315 and regulatory region of inhA (95.23\%) in the MDR Mycobacterium tuberculosis strains isolated in Nepal indicated the potential of a rapid diagnostic test for detection of drug-resistant Mycobacterium tuberculosis [17]. In addition, the multiplex PCR and the strip included an amplification control specific for Mycobacterium tuberculosis isolates and an amplification control detecting all known mycobacteria and members of the group of gram-positive bacteria with a high $\mathrm{G}+\mathrm{C}$ content. The presence of mutations is indicated either by loss of hybridization to the oligonucleotide representing the wild-type sequence and hybridization to the corresponding oligonucleotide representing the mutated sequence or by loss of hybridization to the respective wild-type sequence only.

The Genotype MTBDRplus assay suffers from few limitations for the detection of antibiotic resistance. The genetic basis of resistance is not fully understood for all Mycobacterium tuberculosis isolates. This means that detection of mutation associated with resistant is clinically relevant, but a lack of mutation in the target gene does not necessarily mean that the organism is susceptible to the drug. A variable proportion of resistant isolates were detected as susceptible by MTBDRplus assay. More importantly, little information is available regarding genomic mutation pattern of Mycobacterium tuberculosis associated with RMP and INH resistance in Nepal. However, running a confirmatory conventional DST, when needed, will eliminate such issues.

\section{CONCLUSION}

The Genotype MTBDRplus assay is valuable as a primary screening tool for MDR Mycobacterium tuberculosis isolates/suspects due to its high sensitivity, short working time and easy to include in routine workflow. The assay can even be performed directly from sputum samples of suspected patients. It can be incorporated as a part of procedure in short term treatment course therapy for newly suspected resistant cases. With this rapid and reliable tool, the therapeutic management of patients can be optimized. The containment of MDR-TB strains 
is a big challenge for present and future Nepal. A rapid diagnosis technique like Genotype MTBDRplus assay is essential to counteract such challenges.

\section{ACKNOWLEDGEMENTS}

We would like to thank team of German-Nepal Tuberculosis Project (GENETUP) Hospital, Kathmandu, Nepal for providing laboratory facilities, required reagents and help during research work.

\section{REFERENCES}

1. World Health Organization. Anti-tuberculosis drug resistance in the world Prevalence and trends. WHO/CDS/TB/2007.278.

2. Rieder HL, Watson JM, Raviglione MC et al. Surveillance of tuberculosis in Europe. Working group of the World Health Organization (WHO) and the European region of the International Union against Tuberculosis and Lung Disease (IUATLD) for uniform reporting on tuberculosis cases. Eur Respir J 1996; 9:1097-1104.

3. Pablos-Mendez A, Raviglione MC, Laszlo A et al. Global surveillance for antituberculosis-drug resistance, 1994-1997. World Health Organization-International Union against Tuberculosis and Lung Disease Working Group on Anti-Tuberculosis Drug Resistance Surveillance. N Engl J Med 1998; 338:1641-1649.

4. Nepal Tuberculosis Center (NTC). Annual Report of National Tuberculosis Control Programme Nepal. Government of Nepal, Ministry of Health, Department of Health Services, 2007.

5. Espasa M, Gonzalez-Martin J, Alcaide F. Direct detection in clinical samples of multiple gene mutations causing resistance of Mycobacterium tuberculosis to isoniazid and rifampicin using fluorogenic probes. J Antimicrob Chemother 2005; 55: 860-865.

6. Miotto P, Piana F, Penati V, Canducci F, Migliori GB, Cirillo DM .Use of GenoType MTBDR assay for molecular detection of rifampin and isoniazid resistance in Mycobacterium tuberculosis clinical strains isolated in Italy. J Clin Microbiol 2006; 44:2485-2491.

7. Lemus D, Martin A, Montoro E, Portaels F, Palomino JC . Rapid alternative methods for detection of rifampicin resistance in Mycobacterium tuberculosis.J Antimicrob Chemother 2004; 54: 130-133.

8. Ghimire P, Bhattarai NR, Shrestha B, Rijal B. Resistance to anti-tuberculosis drugs in Kathmandu. SAARC J TB L Dis \& HIV 2004;1: 3942.

9. Heifets L. Conventional methods for antimicrobial susceptibility testing of Mycobacterium tuberculosis. In: Multidrug-resistant Tuberculosis, Ed.: Bastian I, Portaels F. Kluwer Academic Publishers, Dordrecht, The Netherlands, 2000.

10. Hillemann D, Rüsch-Gerdes S, Richter E. Evaluation of the GenoType MTBDRplus Assay for Rifampin and Isoniazid Susceptibility Testing of Mycobacterium tuberculosis Strains and Clinical Specimens. J Clin Microbiol 2007; 45: 2635-2640.

11. Ramaswamy S, Musser JM. Molecular genetic basis of antimicrobial agent resistance in Mycobacterium tuberculosis: 1998 update. Tuber Lung Dis 1998; 79:3-29.

12. Zhang Y, Telenti A. Genetics of drug resistance in Mycobacterium tuberculosis. J Antimicrob Chemother 2000; 42: 235-241.

13. Florence S, Roengsanthia D, Arjrattanakool W, Chuchottaworn C, Chaiprasert A, Franzblau SG . Rapid and simple MTT method for rifampicin and isoniazid susceptibility testing of Mycobacterium tuberculosis. Int J Tuberc Lung Dis 2006; 6:11181120.

14. Cavusoglu C, Gursel D, Aktoprak B. Evaluation of the genotype MTBDRplus assay for the diagnosis of tuberculosis and rapid detection of rifampin and isoniazid resistance in clinical specimens. Turk J Med Sci 2011; 41 (3): 419-425.

15. Somoskovi A, Mester J, Hale YM, Parsons LM, Salfinger M. Laboratory diagnosis nontuberculous mycobacteria. Clin Chest Med 2002; 23:585-597.

16. Bazira J, Asiimwe BB, Joloba ML, Bwanga F, Matee MI. Use of the GenoType MTBDRplus assay to assess drug resistance of Mycobacterium tuberculosis isolates from patients in rural Uganda. BMC Clinical Pathology 2010;10:15.

17. Khadka D. Comparative evaluation of conventional drug susceptibility testing and genotype MTBDRplus assay for multi drug resistant Mycobacterium tuberculosis isolates in Nepal. M.Sc. Dissertation submitted to Department of Microbiology, National College, Kathmandu, Nepal 2008. 